\title{
Cemitério: Patrimônio Cultural Material e Fonte de Turismo como Possibilidades
}

\author{
Cemetery: Cultural Heritage Material and Source of Tourism as \\ Possibilities
}

\author{
Davi Kiermes Tavares ${ }^{1}$; Gisele Dutra Quevedo²; José Paulo Seifert Brahm³; Rodrigo da Costa \\ Segovia ${ }^{4}$ Ronaldo Bernardino Colvero ${ }^{5}$ \\ 1 dakitaa@yahoo.com.br, Instituto Federal de Educação Ciência e Tecnologia da Bahia; \\ 2gisele.quevedo.ppgmspc@gmail.com, Universidade Federal de Pelotas; \\ 3josepbrahm@hotmail.com, Universidade Federal de Pelotas; \\ 4rodrigo.turismo.unipampa@gmail.com, Universidade Federal de Pelotas; \\ 5rbcolvero@gmail.com, Universidade Federal dos Pampas
}

\begin{abstract}
Resumo
A presente comunicação discute o espaço funerário designado cemitério e suas possibilidades, na interface patrimônio cultural material e fonte de turismo. Para estruturá-la, argumentos desenvolvidos por autores como Rezende (2007), Ragon (1981), Martins (1983, 2005), Coelho (1991), Gonçalves (2007), Bellomo (2008), Araújo (2008), dentre outros, são aproveitados. O British Cemetery do Recife é o lugar-exemplo que suscitou e ancora a argumentação escrita.
\end{abstract}

Palavras-Chave: Cemitério, Patrimônio, Turismo, British Cemetery, Espaço.

\begin{abstract}
The present communication discusses the funerary space designated graveyard and its possibilities in the interface cultural heritage material and source of tourism. To structure it, arguments developed by authors such as Rezende (2007), Ragon (1981), Martins (1983, 2005), Coelho (1991), Gonçalves (2007), Bellomo (2008), Araújo (2008), among others, are exploited. The British Cemetery of the Recife is the place-example which aroused and ancora the written arguments.
\end{abstract}

Keywords: Cemetery, Heritage, Tourism, British Cemetery, Space.

\section{Introdução}

A presente comunicação discute o espaço funerário designado cemitério e suas possibilidades, na interface patrimônio cultural material e fonte de turismo, uma vez que ele apresenta sobretudo um système de signes (THOMAS, 1978, p. 9) interpretativos à compreensão da sociedade na qual está inserido; encerra valores memoriais materiais e imateriais de ampla significação histórica, social, ideológica, religiosa, política; tem imanente grande potencial turístico. Tais argumentos possuem lastro no juízo de estudiosos do talhe de 
Ragon (1981), Martins (1983), Coelho (1991), Carrasco (2009), Bellomo (2008), Araújo (2008), dentre vários.

São essas (e outras) compreensões que começam a ser ponderadas no Brasil, a partir dos anos 1925, suscitando debates sobre a questão, os quais vão resultar em posteriores ações concretas de reconhecimento e valorização. Estas ações ainda ocorrem, hoje, de forma residual, infelizmente, a despeito de um perceptível incremento - com o correr dos anos - das políticas públicas voltadas à gestão dos bens culturais, com a inclusão de novos objetos ao rol destes bens e, dentre esses, o cemitério. O tombamento, em nível nacional e estadual, de vários cemitérios pelo país, serve como testemunha disso.

Sucede que o tombamento ${ }^{1}$ é apenas um ato administrativo, um instrumento, que se não vem acompanhado de outras ações em prol da conservação desse monumento, o que resta é o estado de abandono em que se encontram muitos desses já patrimonializados.

Geralmente o espaço cemiterial está associado à perda, tristeza e saudade. No entanto esse local de reverência aos mortos pode desenvolver atividades distintas, como, por exemplo, o turismo. Esse ambiente de utilização pública apesar de ser temido, também desperta admiração. Percebidas como um grandioso museu, as necrópoles são interessantes lugares para, por exemplo, um turismo educativo que contempla cultura, memória, identidade e arte, entre tantos outros significados da vida social.

Ao ultrapassar tabus e preconceitos encontra-se na necrópole uma potencialidade, um lugar com relevância histórico-social, que reúne arquitetura, celebridades, iconologias e iconografias, que exaltam os costumes locais. Nesse sentido o cemitério passa a ser um dos arquivos de registros mais relevante de uma cidade.

O British Cemetery do Recife (conhecido popularmente como "Cemitério dos Ingleses”), o primeiro cemitério da capital do Estado de Pernambuco, construído com essa

\footnotetext{
1 "O termo tombar, empregado em nosso direito, vem do direito português. Usado no Código de Processo Civil luso de 1876 como sinônimo de demarcação, foi neste mesmo sentido empregado no Código de Processo Civil de 1939. Posteriormente, preceitos do Código Administrativo de 1940 assimilaram, definitivamente, o termo na sinonímia de cadastro, uma vez que, usualmente, já se designava por tombo o registro, o arquivo e a catalogação de documentos públicos ou históricos, razão pela qual se chama Torre de Tombo o atual Arquivo Nacional Português. (...) No direito brasileiro, os bens submetidos à proteção do Poder Público por força da lei de tombamento devem ser inscritos nos chamados livros de tombo existentes no Instituto do Patrimônio Histórico e Artístico Nacional - IPHAN, ou no livro apropriado da repartição estadual ou municipal. Daí o entendimento comum de que tombar é inscrever o bem em livros especiais. Entretanto, o tombamento não se resume numa mera inscrição nem se confunde com o conceito de preservação, sendo apenas um instrumento de sua viabilização" (PIRES, 1994, p. 75-76).
} 
finalidade, é um exemplo de cemitério tombado em instância estadual, porém, por vários fatore $^{2}$, hoje relegado ao semiabandono, não explorado apesar de sua fortuna.

\section{Interpretações sobre o espaço cemiterial}

Os estudiosos dos temas relativos à morte e, em particular, ao espaço cemiterial já compreendem o lugar de significados que este ocupa para o entendimento das sociedades nas quais está presente e das quais é testemunha das mais significativas. Tal espaço foi e ainda é lugar onde manifestações culturais ancoram; reproduz em seu interior construções interpretativas do imaginário social.

O surgimento desse espaço no Brasil - e aqui a ênfase recai sobre o cemitério extramuros $^{3}$ - decorre do adensamento das cidades e o aumento da população funerária, mais os problemas epidêmicos, que propiciaram a inadequação e inoperância da maneira de inumação então usual. E também a absorção de nova maneira de pensar a saúde pública pelos sanitaristas locais, que incorporavam tendências europeias.

Com a popularização desse tipo de cemitério, hoje denominado tradicional ou histórico (REZENDE, 2007, p. 27), nas primeiras décadas do século XX, gradativamente o mesmo passou a preservar em seu espaço uma arquitetura detentora de imagens eruditas e populares (folclóricas até), reveladoras de representações dotadas de funcionalidade, valor artístico, simbólico, religioso, ideológico, entre outras.

Algumas dessas interpretações convêm recordar.

\section{a) L'espace de la mort}

O título nomeia o livro de Michel Ragon - renomado crítico e historiador de arte e arquitetura modernas -, no qual analisa o cemitério na perspectiva da arquitetura, da decoração e do urbanismo funerários. Seu conteúdo é uma argumentação construída por analogias. Entre essas está a que propõe o cemitério como a segunda morada, onde o túmulo é a casa e o cemitério é a projeção de um quarteirão, de uma vila ou até mesmo de uma cidade. $\mathrm{O}$ autor observa que nos cemitérios se repetem os elementos arquitetônicos e paisagísticos presentes nas cidades e se reproduz, de fato ou de forma idealizada, a ordem socioeconômica dos vivos. Em suas próprias palavras:

\footnotetext{
${ }^{2}$ Objeto de investigação no mestrado do Programa de Pós-Graduação em Memória Social e Patrimônio Cultural por um dos autores, com ênfase no conceito de valor.

${ }^{3}$ Cemitério extramuros ou campo santo extramuros é o espaço criado fora do âmbito da igreja para fim de inumação.
} 
Chaque tombeau est en effet le double d'une maison, ou d'un appartement et chaque cimetière la projection parallèle d'un village, d'une ville ou d'un quartier.

(...)

Si toute ville moderne suppose un cimetière, tout cimetière ancien, redécouvert, indique qu'une ville disparue se trouvait dans les parages. La nécropole est l'envers de la métropole. L'envers ou l'endroit, c'est selon. Car le cimetière, double idéalisé de la ville, apparaît en même temps comme la reproduction parfaite de l'ordre socio-économique des vivants (RAGON, 1981, p. 37 e 51).

b) Documento iconográfico/espaço de arte e de diálogo

José de Souza Martins, pioneiro em estudos tanatológicos sob a perspectiva das ciências humanas e sociais no país, já sopesava, no século passado, a importância do espaço cemiterial. Em um dos seus vários textos relativos ao assunto, escreveu:

Há mais de vinte anos tenho o hábito de visitar cuidadosamente os cemitérios das localidades que percorro quando faço pesquisa. Os monumentos funerários são ainda o documento iconográfico mais importante para se conhecer, num primeiro relance, a estrutura e a história de uma sociedade (MARTINS, 1983, 258).

De outra feita, o mesmo autor, discorrendo sobre a "cultura funerária no Brasil", em evento que promovia "Reflexões sobre a morte no Brasil", a partir da premissa inicial de sua posição sobre o assunto [Um dos fatores que têm motivado debates e discussões sobre a morte, nos vários campos profissionais, é sem dúvida a nossa inabilidade atual para lidar com ela. Está havendo uma clara perda cultural em relação à questão da morte.], ressalta o desencontro, a incompletude que caracteriza a sociedade brasileira [Numa sociedade como a brasileira, nós somos modernos, mas não tanto. Tudo chegou aqui incompleto, insuficiente. Somos um país numa espécie de transição permanente entre certezas antigas e novas.], para logo interrogar e ao mesmo tempo responder, referindo-se ao cemitério como um lugar de possibilidades relacionais para com a morte. Eis a citação em seu contexto:

(...) Mário de Andrade, figura emblemática da Semana de Arte Moderna, está sepultado no Cemitério da Consolação, em São Paulo, num túmulo cuja falta de estilo e cuja secura estética negam as convicções um dia defendidas pelo ilustre morto que ali se encontra.

Por que ocorrem essas coisas? Porque nós não sabemos lidar com a morte. Nós avançamos e nos tornamos num certo sentido acentuadamente moderno em vários setores da vida, mas permanecemos, no geral, atrasados em relação a esse tema tabu. Abolimos parcialmente os rituais, mutilamos a linguagem simbólica da nossa relação com o que vem depois da vida, dizemos que nada há depois daqui, mas não temos certeza disso. Em nome dessa falta de certeza, abolimos condutas e procedimentos como se certeza tivéssemos. É essa incerteza que pede os ritos substitutivos para essa renúncia, ritos que não criamos nem sabemos criar. $E$ verdade que nossos cemitérios, especialmente das grandes cidades, têm inúmeras provas de busca de um caminho de diálogo com a morte por meio da arte. Mas essa não é a regra (MARTINS, 2005, p. 74-75 - destacou-se). 
c) Espelho da sociedade

Por derradeiro, a interpretação do historiador Antônio Matias Coelho, a qual resulta e reflete seu trabalho na montagem do Núcleo de Funerária do Museu Municipal de Chamusca, o único do seu gênero em Portugal. Localizado no cemitério municipal da vila da Chamusca, componente do Distrito de Santarém, o Núcleo completa o "museu-cemitério" que se apresenta, aos olhos de quem o visita, dotado de uma riqueza evidente em si mesmo. O seu modo de interpretar o espaço cemiterial e o que ele contém se traduz em depoimento inconteste (que, de certa forma, conecta-se com os depoimentos anteriores). Ele assim considera: “(...) os cemitérios funcionam como espelhos das aldeias, vilas ou cidades que os produzem. O conhecimento de uma qualquer comunidade ficará sempre incompleto se não incluir o seu cemitério (COELHO, 1991, p. 8).

Esse conjunto sucinto de depoimentos - espécie de "fortuna crítica" - testifica outra maneira de pensar o cemitério. Tais ideias contribuem para que ele seja apreciado e considerado e apropriado como um bem de referência cultural dos mais singulares para determinado grupo ou lugar sociais.

\section{Cemitério como patrimônio cultural material}

A expressão "patrimônio cultural brasileiro" consagra o entendimento de que nela estaria inserido o patrimônio cultural como um todo, seja de interesse da União, dos Estados ou dos Municípios. Tem-se, na verdade, um patrimônio cultural com sentido de universalidade. Entende Silva (2001) que o patrimônio cultural brasileiro - modo de preservar os valores das tradições da experiência histórica e da inventividade artística - compreende o patrimônio cultural nacional integrado pelos bens de interesse nacional; o patrimônio estadual integrado pelos bens de interesse apenas do Estado interessado; o patrimônio cultural municipal de interesse de cada município que o tenha formado.

O cemitério se coaduna a essa compreensão de patrimônio cultural, posto que contém valores diretamente ligados aos bens materiais e aos bens imateriais (de valor simbólico, ligados às crenças e ao culto popular, que não serão contemplados neste texto por fugirem ao escopo do mesmo).

Três importantes valores patrimoniais podem estar relacionados aos bens materiais. São aqueles de caráter ambiental/urbano, de caráter artístico e de caráter histórico (CARRASCO, 2009, p. 24-28). 
O valor de caráter ambiental/urbano está relacionado aos espaços destinados ao cemitério que, muitas vezes, estão inseridos nos núcleos históricos das cidades e representam espaços abertos que preservam suas áreas verdes.

O valor artístico, por sua vez, aos artefatos integrados à arquitetura tumular com função ornamental, pela sua riqueza de elaboração, especialmente, em ferro fundido e forjado, bem como ao mobiliário urbano e às obras de arte de artistas renomados ou não.

Quanto ao valor histórico, considera-se que é nesse espaço que repousam os restos mortais de pessoas, ilustres ou não, que contribuíram de alguma forma para a história da humanidade. São espaços de memória, onde as lápides registram dados importantes para a história - datas, nomes e epitáfios.

No Brasil e no exterior, há algum tempo, já existem iniciativas - como, por exemplo, associações, declarações, leis, tombamentos e atividades turísticas -, que refletem outra consciência sobre a preservação do patrimônio funerário.

Conforme Castro (2008, p. 82-87), durante as décadas de 1960 e 1970, o interesse pelos cemitérios, despertado pelos seus valores patrimoniais, começa a aparecer e são desse período as primeiras publicações sobre o tema da arte funerária no Brasil. Embora, algumas das ações direcionadas ao patrimônio funerário no Brasil indicarem que a preocupação com a proteção dos cemitérios já estão presentes nas primeiras décadas do século XX.

Pesquisando nos arquivos do $\mathrm{IPHAN}^{4}$, a autora registrou quinze tombamentos direcionados a cemitérios e partes de seus conjuntos, como túmulos, portões e inscrições tumulares. O levantamento de dados considerou os tombamentos nos quais cemitérios e partes destes participaram da ação, ou seja, foram citados na inscrição ou no pedido de proteção do bem.

Ela constata que

\begin{abstract}
Na tabela de tombamentos de patrimônio funerário do IPHAN, os processos e os pareceres apresentados, evidenciaram alguns valores atribuídos aos cemitérios em seus tombamentos. Ações que reiteraram a forma como este órgão relaciona o que deve ser preservado por seu valor para a memória coletiva do país. No caso dos cemitérios, é possível perceber, que os tombamentos, em sua maioria, são direcionados, principalmente, aos seus elementos materiais que ganham destaque em túmulos, estátuas e pórticos de entrada. Outros valores como o caráter ritual
\end{abstract}

\footnotetext{
${ }^{4}$ Instituto do Patrimônio Histórico e Artístico Nacional sucedeu ao SPHAN (Secretaria do Patrimônio Histórico e Artístico Nacional), órgão que realizou o primeiro levantamento dos bens de interesse histórico e cultural nacionais a serem salvaguardados (PELEGRINI, 2006). Apesar do SPHAN ser apontado como órgão pioneiro nas ações de preservação pela maioria dos estudiosos, não se pode deixar de citar a existência da Inspetoria de Monumentos Nacionais, subordinada ao Museu Histórico Nacional, criada em 1934 através do Decreto $\mathrm{n}^{\circ} 24.735$, que iniciou a organização de um serviço de proteção aos monumentos históricos e às obras de arte tradicionais do país.
} 
destes espaços, mesmo em projetos de preservação atual, são pouco citados (CASTRO, 2008, p. 80, destacou-se).

Fora as iniciativas federais, como as do IPHAN mencionadas pela pesquisa de Castro (2008), também alguns Estados já incluem os cemitérios em seu conjunto de bens patrimoniais. É o caso do Estado de Pernambuco e do cemitério que serve de ensejo desta reflexão: o British Cemetery.

\section{Cemitério como fonte de turismo}

Pensar o cemitério como fonte de turismo implica compreender os vínculos que os unem, e também o como eles se estabelecem.

Moesch (2002, p. 9), conceituando o que seja turismo, diz:

O turismo é uma combinação complexa de inter-relacionamentos entre produção e serviços, em cuja composição integram-se uma prática social com base cultural, com herança histórica, a um meio ambiente diverso, cartografia natural, relações sociais de hospitalidade, troca de informações interculturais. O somatório desta dinâmica sócio cultural gera um fenômeno, recheado de objetividade/subjetividade (...).

Por ser uma atividade dinâmica, o turismo não se restringe a locais pré-determinados. Por esse motivo, o cemitério também é tido com um produto turístico, principalmente quando apresenta um acervo histórico, artístico e arquitetônico dos mais belos e diversificados.

Para a atividade turística, Queiroz (2007) afirma que houve um aumento na procura pelo espaço cemiterial, a partir década de 1990. O autor relata eventos sobre as necrópoles realizados em alguns países, como o Congresso Internacional sobre Cemitérios Contemporâneos em Sevilha (1992), o primeiro Simpósio Internacional de Arte Cemiterial, em Wroclaw Polónia (1993) e a criação da Association of Significant Cemeteries in Europe (ASCE) (2001), que visa promover o turismo em rede.

Neste sentido, a afirmação de Afonso (2010, p. 16), se faz pertinente:

(...) percebe-se que o uso do espaço cemiterial apresentado de forma diferenciada, fugindo da função para o qual foi concebido, retira a intencionalidade dada na criação do cemitério e cria uma nova forma de lazer, escapando do lazer mercadoria (...).

Os conceitos e expressões relacionados ao espaço cemiterial e turismo são diversos. Turismo mórbido relacionado com a morte (BLOM, 2000). Para o autor, esse tipo de turismo assume duas formas principais: aquela que "se foca na morte súbita e que atrai rapidamente 
grande número de pessoas", por um lado, e, por outro, o turismo "baseado em atrações e relacionado com uma morbidez artificial” (BLOM, 2000, p. ).

Seaton (1996) introduz o conceito de Thanaturismo, ou seja, o turismo em que a "thanatopsis" (contemplação da morte) é o principal interesse dos turistas. Para Seaton, este interesse tem as suas raízes na Idade Média, embora se tenha vindo a intensificar desde o Romantismo.

A definição de Thanaturismo dada pelo autor é:

(...) a viagem a um local, completa ou parcialmente, motivada pelo desejo de (estabelecer) encontros reais ou simbólicos com a morte, particular mas não exclusivamente com a morte violenta, que podem ser activados em grau variável pelas características específicas das pessoas cujas mortes são os seus objectos focais (SEATON, 1996, p. 40).

O que é denominado Turismo Cemiterial surge de uma mescla entre o Turismo Negro (Dark Tourism) e o Turismo Cultural, não existindo uma ideia clara e objetiva acerca desta temática (PEREIRA, 2012). Mas, levando-se em conta as motivações ${ }^{5}$ para a prática deste tipo de turismo, pode-se afirmar que pode ser compreendido como um desdobramento do Turismo Cultural (AFONSO, 2010; DIAS; AGUIAR, 2002).

Foley e Lennon (1996) cunharam o termo "Turismo Negro", que desde então é o mais amplamente aceite e utilizado na literatura. Stone (2006) explica que a escolha do adjetivo "Negro" simplesmente pretende aludir a práticas aparentemente perturbadoras bem como a produtos e experiências mórbidos, que constituirão a base deste tipo de turismo.

Para Foley e Lennon, Turismo Negro é "o fenômeno que engloba a apresentação e consumo (pelos visitantes) de morte e locais de catástrofe reais e mercantilizados" (1996, p. 199). Os autores veem o Turismo Negro como algo recente, uma "intimação da pósmodernidade" (LENNON; FOLEY, 2000, p. 11), e apresentam três motivos para essa convicção.

Um desses motivos é que o interesse do público nas mortes ou catástrofes está dependente de uma compressão espaço-temporal, ou seja, diretamente relacionado com a capacidade dos media em difundi-las.

\footnotetext{
5 Tais como: contemplação de esculturas de artistas, amplitude dos espaços ajardinados, bucólicos e aconchegantes, identificação da arquitetura das diversas épocas, notoriedade de personalidades sepultadas, associação a excertos de livros ou filmes, (...) visitas a campas de entes queridos, (...) eventos culturais baseados em mitos e lendas. Cf. Afonso, 2010.
} 
Outro dos motivos apontados pelos autores é que, tal como o conceito de pósmodernidade, a maioria dos locais de Turismo Negro põe em causa a racionalidade, ordem e progresso inerentes à modernidade.

Finalmente, Lennon e Foley defendem o argumento de que há uma crescente perda de definição da fronteira entre a mensagem (política e/ou educacional) que se quer passar e a comercialização dos locais de Turismo Negro.

Assim sendo, para esses autores é necessário que os eventos que dão origem às atrações possam ser validados, isto é, que haja alguém que os tenha testemunhado e que possa atestar a sua veracidade, e que elas induzam no visitante um sentimento de ansiedade em relação à modernidade. Por estes motivos, eles encaram o Turismo Negro como um fenómeno recente e principalmente ocidental, baseado em visitas "por serendipidade 6 , itinerários de companhias turísticas, ou [d]os meramente curiosos que por acaso estavam nas redondezas" de um local de Turismo Negro.

Para Lennon e Foley (2000), essa motivação não é importante, mas sim o local que visitam e a reacção que ele provoca nos visitantes. A ideia defendida por eles, e em parte também por Rojek (1997) que enquadra o Turismo Negro num horizonte temporal recente, é bastante contestada na literatura. Por exemplo, Beech (2000, apud SHARPLEY, 2009) afirma que os edifícios militares são desde há muito atrações turísticas, e Stone (2006, p. 147) defende que "os exemplos iniciais de Turismo Negro podem ser encontrados no patronato dos jogos gladiatoriais Romanos", tendo o Coliseu de Roma sido uma das primeiras atrações de Turismo Negro. O mesmo autor afirma ainda que as execuções públicas "desde o período medieval até ao século XIX” constituem também manifestações de Turismo Negro.

Sharpley (2009, p. 4) sintetiza do seguinte modo a visão dos autores que defendem a antiguidade da prática de Turismo Negro: “desde que as pessoas são capazes de viajar, elas são atraídas - propositadamente ou não - para locais, atrações ou eventos que estão ligados de uma forma ou de outra com morte, sofrimento, violência ou catástrofe".

Atualmente, uma das definições de Turismo Negro mais utilizada pelos acadêmicos é de Stone (2006, p. 146), que define o Turismo Negro como "o ato de viajar para locais associados com morte, sofrimento, e o aparentemente macabro". No mesmo artigo, o autor apresenta uma outra definição que parece ser mais expressiva: “o fenómeno pelo qual as pessoas visitam, intencionalmente ou como parte de um itinerário recreativo mais amplo, a

\footnotetext{
6 “Serendipidade" vem do inglês "serendipity", e diz respeito à descoberta de algo agradável por acaso.
} 
diversa gama de locais, atrações e exposições que oferecem uma (re/a)presentação de morte e sofrimento" (STONE, 2006, p. 146).

Quanto ao turismo cultural, Richards e Bonink (1995, p. 56) afirmam que é "o movimento de pessoas até atrações culturais fora do seu local habitual de residência, com o objetivo de ganhar informação, experiências e satisfazer as suas necessidades culturais".

Por sua vez, Craik (1997) entende o turismo cultural como a visita a outras culturas e sítios para aprender, conhecer o seu modo de vida, o património cultural e as suas artes, o que também se enquadra nas visitas a cemitérios.

Não há uma padronização das denominações, talvez por se tratar de uma área de pesquisa recente no turismo, uma área pouco explorada em termos conceituais. No entanto, é possível perceber que as denominações turísticas para essa atividade trazem a ideia de algo funesto. Vale ressaltar, porém, que não necessariamente um cemitério será utilizado para visitas com o interesse mórbido. A arte tumular, iconografia, arquitetura, história e personalidades ali sepultadas são os itens que mais motivam o turista a se deslocar até as necrópoles.

Existem associações que estudam o cemitério como um patrimônio e, também, como temática para o turismo. É o caso, por exemplo, da Association of Significat Cemeteries in Europe (ASCE), composta por organizações públicas e privadas que estudam os cemitérios como atrativos turísticos. Outra entidade nesse sentido é a National Federation of Cemetery Friends no Reino Unido, criada em 1986 para conservação do patrimônio fúnebre (limpeza, restauro) da vida biológica existente no cemitério.

Pensar o turismo cemiterial, na estrutura atual, parece ser algo inovador; no entanto, as viagens com destinos às sepulturas não são recentes. Aquele que é considerado o primeiro guia turístico impresso da história surgiu no século XII e indicava aos peregrinos, o caminho do sepulcro do aposto Tiago, em Santiago de Compostela.

No ano de 1139, sob encomenda do Papa Calixto II, o sacerdote francês Aymeric Picaud escreveu o primeiro guia de acesso a Santiago, o Códex Calixtinus, descrevendo todos os passos do trajeto à cidade Santa, sendo considerado o primeiro guia de turismo da história, pois descrevia detalhes como, os costumes, os lugares, as pessoas, paisagens, comidas, hospitais (AFONSO, 2010, p. 10).

Segundo Queiroz (2007, p. 6), o Turismo Cemiterial traz mesmo vantagens, pois

permite sensibilizar as autoridades que tutelam os cemitérios para a sua conservação e restauro (...), o fato das visitas se tornarem geralmente muito demoradas, sobretudo nos cemitérios ricos em obras e como tal, muitas vezes implicam a estadia 
por mais um dia (...) e não proporcionarem impactes turísticos e socioculturais, na medida em que não existem conflitos de interesses com os residentes.

Não há motivos para que não ocorra a atividade turística nesse local, ao pensar-se que o cemitério é também um lugar de urbanidade, de cidadania e cultura. Esse turismo se apresenta crescente e escapa da lógica dos destinos massivos. São experiências significativas, pelo fato de o turismo cemiterial envolver arte, cultura, história e memória. Trata-se de uma possibilidade de troca de bens simbólicos em um cenário que é multidisciplinar e educativo.

Como chamam atenção Osman e Ribeiro (2007), hoje, em vários países do mundo, o cemitério já é um espaço consolidado como um ponto turístico. Nesse sentido, os mais conhecidos dentro da rota turística pelo mundo estão os europeus, começando pelos franceses (Père Lachaise, Montparnasse, Montmartre); seguidos pelos cemitérios ingleses (Highgate e Golders Green Crematorium). Na América do Sul lidera o Cemitério da Recoleta, em Buenos Aires, seguido dos cemitérios brasileiros, da Consolação e do Morumbi, em São Paulo, e São João Baptista, no Rio de Janeiro.

Ainda, segundo os autores referendados,

\begin{abstract}
Como ponto turístico consolidado nos mais diferentes países do mundo, os cemitérios atraem romarias de visitantes interessados em conhecer túmulos de personalidades mundiais da literatura, das artes, da política, da história como também para apreciar túmulos e jazigos que podem ser vistos como verdadeiras obras de arte. Além de sua importância histórica, os cemitérios são ainda vistos como locais por onde se podem percorrer jardins arborizados, alamedas floridas e desfrutar de momentos de paz e tranqüilidade como numa ilha no meio do caos urbano das grandes cidades (OSMAN; RIBEIRO, 2007, p. 3)
\end{abstract}

\title{
5. O British Cemetery do Recife
}

Conhecido popularmente como "Cemitério dos Ingleses", a construção deste cemitério é consequência da presença inglesa e suas influências no cotidiano das cidades do BrasilColônia, que logo seria elevado à categoria de Reino Unido a Portugal. Especialmente naquelas onde se localizavam os principais portos coloniais e nas quais houvesse grande presença de britânicos. Tais como Recife, Salvador e Rio de Janeiro.

O sepultamento dos não católicos, entre os quais os estavam os ingleses, foi preocupação de D. João VI a partir de casos específicos, e também decorrência dos Tratados entre Inglaterra e Portugal, de 1810, e de forma especial a sua ratificação pelos termos da Carta Régia. ${ }^{7}$

\footnotetext{
${ }^{7}$ Carta Régia é o nome dado ao documento oficial assinado por um monarca que segue para uma autoridade sem passar pela chancelaria, geralmente contendo determinações gerais e permanentes.
} 
Tendo-se estabelecido em diversas cidades, os ingleses partilharam igualmente de diversas situações em cada uma delas: as epidemias, acidentes, mortes naturais e as condições insalubres de trabalho.

Segundo o historiador pernambucano José Antônio Gonsalves de Mello, o inglês Daniel Savege, teria sido um mestre na escuna Samuel, tendo falecido na cidade do Recife, no dia 10 de janeiro do ano de 1802, e foi sepultado "em cumprimento da ordem recebida, no fosso da fortaleza do Brum" (MELLO, 1972, p. 12).

Tempos passados, quando o ocorrido chegou ao conhecimento de seus contemporâneos, os britânicos residentes na cidade, temendo passarem pelo que a prática estabelecida na Capitania de Pernambuco determinava - "de serem enterrados nas praias, onde se lançam os cadáveres dos negros não batizados, os vassalos britânicos da religião protestante que ali morrem” (MELLO, 1972, p. 12) -, sabedores de que no Rio de Janeiro e em Salvador foram destinados terrenos para servir de cemitérios aos súditos britânicos protestantes, "solicitaram a seu representante, o Visconde Strangford, que lhe fosse concedido direito igual ao obtido pelos seus compatriotas na Corte e em Salvador" (MELLO, 1972, p. 12).

Ainda segundo o historiador mencionado, no dia 18 de novembro de 1813, o ministro dirigiu-se ao Príncipe Regente, relatando o pedido dos súditos britânicos em Recife, solicitando uma área para o sepultamento dos ingleses que ali falecessem. O Príncipe Regente expediu no dia 20 de novembro de 1813 ordens ao governador e capitão daquela Capitania no sentido de que um terreno fosse adequado para os fins de instalação de um cemitério dos ingleses, visto que sua Real Fazenda "se propõe dar em propriedade o sobredito terreno à Nação Britânica" (MELLO, 1972, p. 13).

No ano de 1814, o governado da Capitania de Pernambuco - o Capitão-General Caetano Pinto de Miranda Montenegro, cumprindo ordens recebidas do Príncipe Regente, mandou demarcar, no local conhecido como Santo Amaro das Salinas, um terreno de 120 palmos de frente por 200 de fundo, o qual foi desapropriado e doado ao cônsul inglês John Lempriere, destinado à instalação de um cemitério para os ingleses naquela Capitania. O local era distante do centro urbano da cidade do Recife, próximo ao Lazareto de Santo Amaro, onde ficavam em quarentena, os escravos recém-chegados da África (PARAÍSO, 1997, p. 36). O terreno escolhido, segundo Mello, estava situado numa estrada que ligava a cidade do Recife a Olinda (MELLO, 1972, p. 15).

É preciso que se diga, no entanto, recorrendo-se uma vez mais à argumentação de Mello, que não há elementos documentais que permitam indicar com exatidão a data, nem 
mesmo o ano, do estabelecimento do cemitério. "A inexistência de um clérigo anglicano em Pernambuco, que presidisse as cerimônias de enterramento, parece explicar a falta de informações acerca dos primeiros tempos" (MELLO, 1972, p. 15).

O Cemitério dos Ingleses do Recife (figuras 1 e 2), construído e instalado na Estrada Luiz Rego, no local conhecido à época como Santo Amaro das Salinas, atualmente tem como endereço a Avenida Cruz Cabugá, 876, bairro de Santo Amaro. Hoje, ocupa uma área de $1.700 \mathrm{~m}^{2}$, aproximadamente (a área original foi de 1.161,6 $\mathrm{m}^{2}$; chegou a ter: $2.200 \mathrm{~m}^{2}$ ). Possui cerca de duzentas lápides e realiza até 10 sepultamentos/ano.

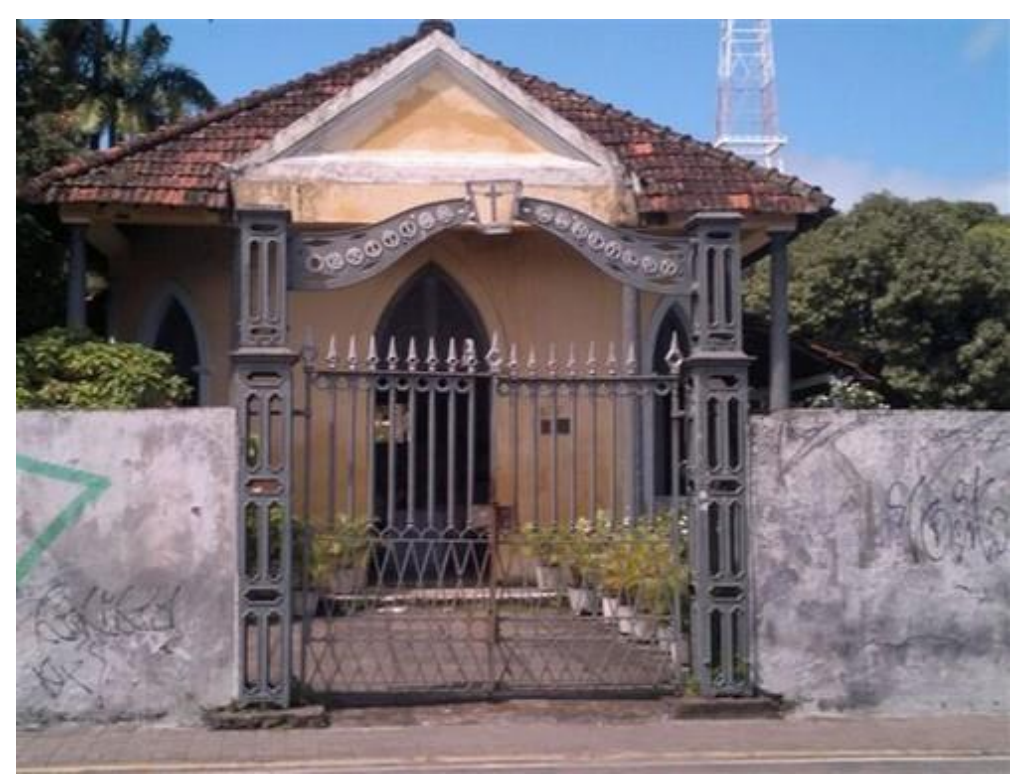

Figura 1 - Entrada do Cemitério dos Ingleses com seu artístico portão. Fonte: acervo do autor.

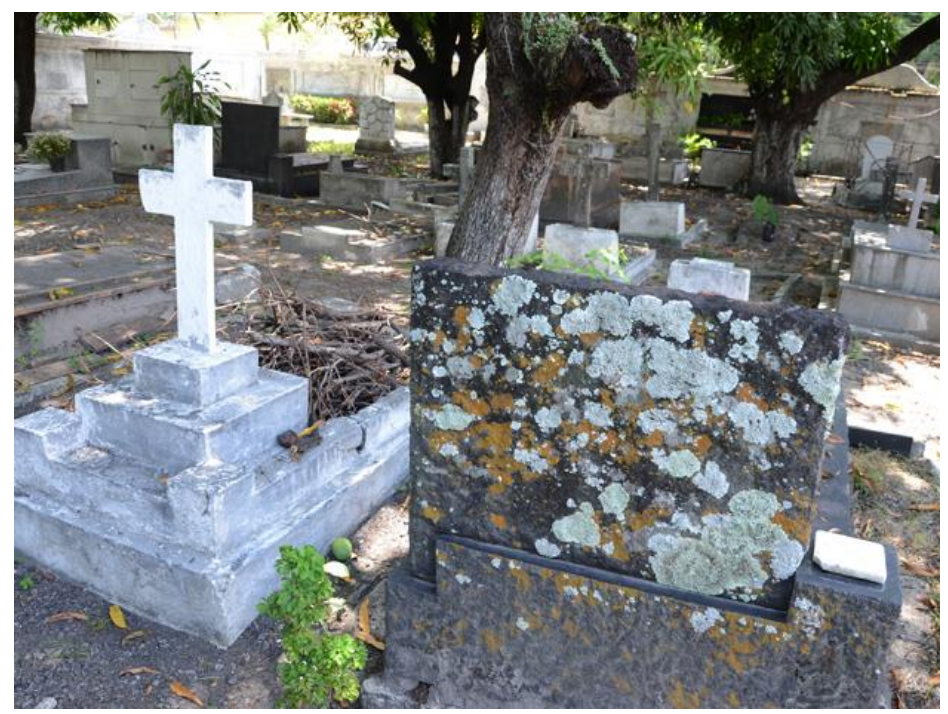

Figura 2 - Vista interna de parte do Cemitério dos Ingleses. Fonte: acervo do autor. 
Nele estão sepultados os corpos não apenas corpos de britânicos protestantes. Estão enterrados outros estrangeiros de diversas nacionalidades, como também brasileiros não protestantes.

Nesse cemitério também permanecem os restos mortais do general Abreu e Lima, que, na época, embora cristão, e não declaradamente um protestante, não pôde ser enterrado nos cemitérios católicos em razão de querela estabelecida pelo bispo católico d. Cardoso Ayres. O bispo alegou, entre outras razões, que, “com pesar", entendera que o general não reconhecia o mistério da Santíssima Trindade, além de repelir a ideia da confissão auricular (RODRIGUES, 2005, p. 150).

Em sua lápide, encontra-se grafado o indicativo da intransigência:

Aqui jaz o cidadão brazileiro general José Ignacio D'Abreu e Lima propugnador esforçado da liberdade de consciencia. Falleceu em 08 de março de 1869. Foi-lhe negada sepultura no Cemeterio público pelo bispo Francisco Cardozo Ayres. Lembrança de seus parentes (figura 3).

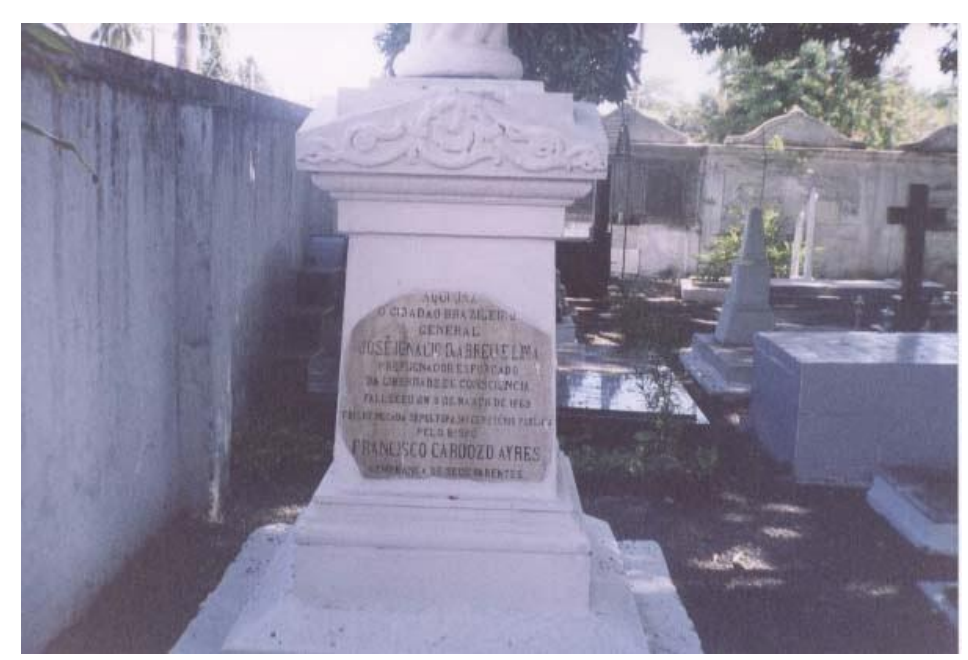

Figura 3 - Lápide do túmulo de Abreu e Lima.

Fonte: atrativope.blogspot.com.br.

O Cemitério dos Ingleses do Recife, com características arquitetônicas próprias, as quais seguem o estilo despojado dos ingleses, tem em seu portão principal uma referência singular que o destaca dos demais daquela cidade. Ostentando a tradicional inscrição British Cemetery em seu frontispício (figura 4), o portão do Cemitério dos Ingleses do Recife se identifica de imediato com a comunidade britânica local por sua imponência histórica tendo sido ali instalado no ano de 1852, pela Fundação Inglesa D'Aurora (VAISENCHER, 2003). 


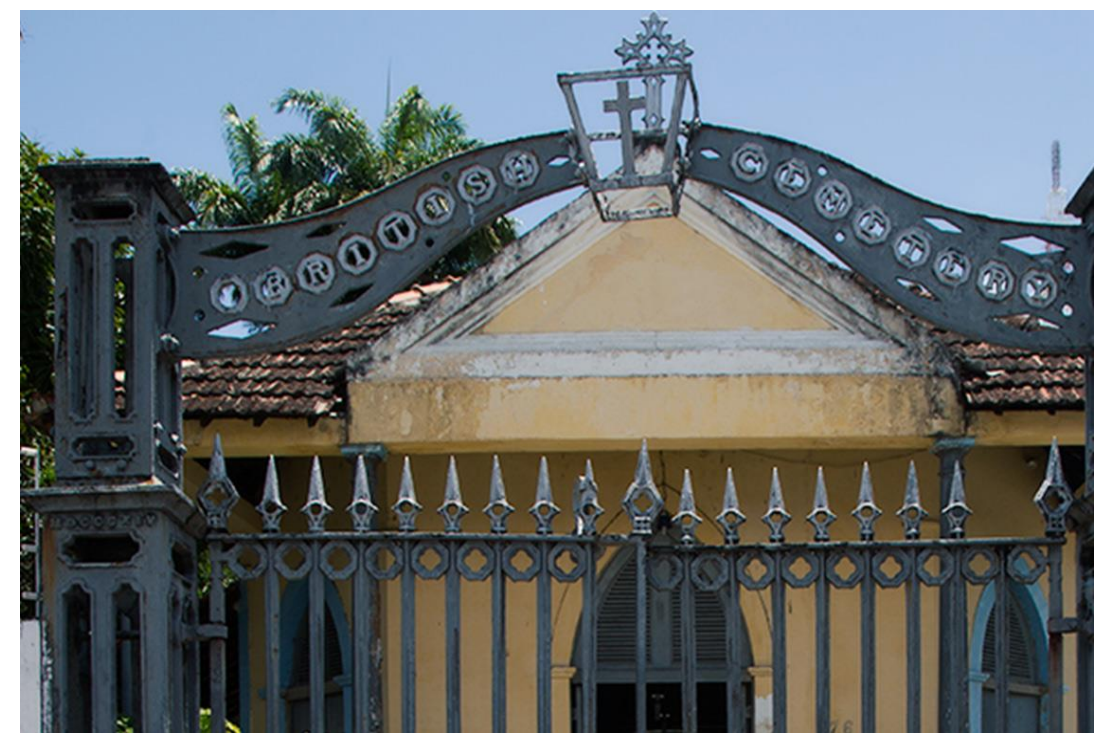

Figura 4 - Portão do Cemitério dos Ingleses e seu frontispício. Fonte: Acervo do autor.

\subsection{O British Cemetery do Recife patrimonializado}

Gilberto Freyre, em seu Guia Prático, Histórico e Sentimental da Cidade do Recife (2013 [1934]), publicado nos anos trinta do século passado (época em que, como já se mencionou, iniciava-se no Brasil a discussão valorativa de cemitérios como bens culturais a serem preservados), destacava, entre os cemitérios da cidade, pela importância histórica e o valor de alguns dos seus monumentos, o Cemitério dos Ingleses. O valor patrimonial, conforme aclarado acima, é, nele, prontamente identificável.

Entretanto, somente nos anos oitenta do século referido, proposta de Tombamento foi empreendida com relação a esse monumento, à época, já compondo o sítio histórico ${ }^{8}$ constituído juntamente com a Igreja de Santo Amaro das Salinas, em Zona Especial do Patrimônio Histórico ${ }^{9} 23$ (ZEPH 23) - uma das trinta e três Zonas Especiais de Preservação do Patrimônio Histórico-Cultural da cidade do Recife. A iniciativa partiu da Fundação do

Patrimônio Histórico e Artístico de Pernambuco (FUNDARPE), através do OF.-DP-N ${ }^{\circ}$ 151/81 (Recife, 18 de março de 1981).

Após desencontro de interesses, que demandou tratativas em período relativamente longo entre a FUNDARPE e o Conselho Estadual de Cultura, finalmente este, através da

\footnotetext{
${ }^{8}$ Sítio Histórico Santo Amaro das Salinas é assim oficialmente chamado.

9 “Consideram-se Zonas Especiais de Preservação do Patrimônio Histórico Cultural - ZEPH -, as áreas formadas por sítios, ruínas e conjuntos antigos de relevante expressão arquitetônica, histórica, cultural e paisagística, cuja manutenção seja necessária à preservação do patrimônio histórico-cultural do Município." (Art. 14, Lei No 16.176/96 - ESTABELECE A LEI DE USO E OCUPAÇÃO DO SOLO DA CIDADE DO RECIFE. Disponível em: <http://www.recife.pe.gov.br/pr/leis/luos/soloZEPH.html $\geq$. Acesso em: 12 dez. 2013.)
} 
Resolução no 15/83 (Recife, 6 de dezembro de 1983), resolve declarar o Tombamento do Cemitério dos Ingleses.

Em sequência, o então Governador do Estado de Pernambuco, Roberto Magalhães Melo, assina o Decreto no 9131 (Decreto de Tombamento, na Categoria de Sítio Histórico, conforme registro no Livro III, Fl. 01, ato $\mathrm{n}^{\circ}$ 7, do Registro de Tombo), de 23 de janeiro de 1984, homologando a Resolução do Conselho Estadual de Cultura declaratória de Tombamento do Cemitério dos Ingleses. ${ }^{10}$

Não obstante o reconhecimento patrimonial, outras ações ficaram pendentes para a consolidação do monumento como um bem cultural (da cidade, do Estado, do país), assim como possibilitar uma preservação constante e extrair "dividendos" de todo o seu "capital social”. O que não ocorreu e não ocorre com o British Cemetery do Recife. Ao ponto de suscitar publicidade negativa (denúncia mesmo) através de diversos meios midiáticos. ${ }^{11}$

Uma delas, pelo seu aspecto didático e ilustrativo, e que merece ser transcrita (apesar de sua extensão), provém de um herdeiro de ingleses, dos mais reconhecidos e esclarecidos na sociedade recifense contemporânea e, portanto, ligado ao cemitério de alguma forma, o qual lamentava a negligência com o cemitério. Rostand Paraíso, em Esses Ingleses..., obra que já se referenciou em outra parte deste texto, expressa seu posicionamento dessa forma:

Nos idos de 1981, o [então] Presidente da Venezuela, Herrera Campins, anunciou
visita a Pernambuco. Fazia questão de passar na cidade do Recife para reverenciar a
figura de Abreu e Lima, que no Panteon venezuelano é considerado um dos seus
maiores heróis. Abreu e Lima, por picuinhas do bispo Cardoso Ayres, teve de ser
sepultado no Cemitério dos Ingleses pelo fato de ser maçom. (...) Abreu e Lima
curtia no Cemitério dos Ingleses o maior desprezo dos seus conterrâneos. Às
pressas, graças à exigência do Presidente Venezuelano, o velho cemitério foi

${ }^{10} \mathrm{O}$ Tombamento apresenta algumas peculiaridades, quais sejam:

a) reforçou a proteção patrimonial, ao nível estadual, visto que o monumento já estava sob a guarda do município (PROCES. TOMBAMENTO, FI. 1, tomo 5);

b) o Consulado inglês do Recife, na pessoa do Cônsul Miguel Otávio de Melo Jr., anuiu ao pedido de tombamento com a seguinte ressalva: "continuaremos [os ingleses] a usar o local tombado, como cemitério, como vimos procedendo desde o ano de 1813 (sic)" (PROCES. TOMBAMENTO, FI. 3, tomo 3);

c) o cemitério tem um administrador próprio, não remunerado, eleito pelas pessoas (ingleses ou descendentes de ingleses, em sua grande maioria) que ali possuem jazigos e que, "com a finalidade de discutir assuntos ligados ao mesmo, se reúnem, quando necessário, em dependências do Country Club, conservando uma tradição" (PARAÍSO, 1997, p. 36).

${ }^{11}$ Nesse sentido, cf. as reportagens:

a) Cemitérios dos Ingleses está em estado de abandono. Disponível em: <http://www.leiaja.com/noticias/2012/11/16/cemiterio-dos-ingleses-esta-em-estado-de-abandono/> Acesso em: 20 set. 2013.

a) Abandono no Cemitério dos Ingleses, o primeiro de Pernambuco. Recife: TV JORNAL, 2013. 2' 18". Disponível em: <http://tvjornal.ne10.uol.com.br/noticia/ultimas/2013/02/18/abandono-no-cemiterio-dosingleses-o-primeiro-de-pernambuco-7667.php> Acesso em: 12 dez. 2013. 
reformado e o túmulo do general, filósofo e escritor, recebeu o tratamento que os grandes vultos merecem.

(...)

No dia 13 de agosto de 1981, com a presença do Governador de Pernambuco, Marco Maciel, do seu chefe do cerimonial, Augusto Rodrigues Filho, do Conselheiro Político da Embaixada Britânica no Brasil, John Flynn, do cônsul honorário da GrãBretanha no Recife, Miguel Otávio de Mello Jr., do administrador do Cemitério, Edward Polloc, e de vários familiares do general Abreu e Lima, residentes no Recife, o presidente Luiz Herrera Campins, numa cerimônia simples, iniciada às 11.30 horas (sic) e que durou pouco mais de 15 minutos, após ouvir os hinos nacionais da Venezuela e do Brasil, executados pela Banda da Polícia Militar de Pernambuco, depositou uma coroa de flores no túmulo, ali permanecendo em silêncio durante um minuto. Em seguida, retirou-se, acompanhado de sua comitiva, rumando para o Hotel de Quatro Rodas, em Olinda, e, cerca de uma hora depois, para o Palácio do Campo das Princesas, onde foi agraçiado com a comenda da Ordem do Mérito Guararapes, a maior condecoração do Estado de Pernambuco.

Com esse episódio, só podemos lamentar que, ao contrário de outros países, que sabem cultuar a memória dos seus mortos ilustres - haja vista o túmulo do general Grant, em New York, o de Kennedy, no Cemitério de Arlington, e de tantos outros mais, espalhados pelo mundo inteiro -, nós deixamos no esquecimento um herói da envergadura do general Abreu e Lima; e que o Cemitério dos Ingleses, que, por um conjunto de circunstâncias especiais, abriga os seus restos mortais, em vez de ser um local visitado pelos escolares, professores e todos aqueles que se interessam, ou deveriam se interessar, pela nossa história, esteja relegado a um quase abandono por parte de nossas autoridades (PARAÍSO, 1997, p. 37-38, destacou-se).

\section{Conclusão}

Se, por um lado, o espaço cemiterial já é reconhecido e patrimonializado, ainda que não satisfatoriamente em quantidade e qualidade, no Brasil e no mundo, a questão da preservação/conservação, que deveria ser o desdobramento natural desse status, apresenta-se como problema a ser suplantado. Por outro lado, a exploração desse lugar em termos turísticos, como já ocorre em diversos lugares mundo afora, com a sua inserção em roteiros turísticos, já não é algo improvável, agora, como era em tempos outrora.

O turismo cemiterial, a educação patrimonial, as pesquisas acadêmicas e textos que proponham percepção positiva do seu simbólico e desmistifiquem preconceitos relacionados à morte e ao l'espace de la mort, intervenções públicas e privadas mais efetivas voltadas à sua preservação, todo esse conjunto de iniciativas e atividades assume configuração que merece ser exponencializado com a máxima brevidade e urgência como recursos à superação.

A situação do British Cemetery do Recife, igual à de tantos outros cemitérios do país, reclama ações que ajudem em sua preservação/conservação; que o retire da (quase?) invisibilidade em que se encontra, e explore a riqueza de possibilidades que possui em diversas perspectivas, sobretudo do patrimônio e do turismo. 


\section{Referências}

AFONSO, Liliane Rosa Gomes. Turismo Cemiterial: O cemitério como espaço de lazer. (Monografia da Universidade Federal de Minas Gerais, 2010). Disponível em: <http://biblioteca.igc.ufmg.br/monografias/Turismo/2010/Liliane\%20Rosa\%20Gomes\%20Afonso/tcc 81.pdf >. Acesso em: 31 ago. 2013.

BLOM, Thomas. Morbid tourism - a postmodern market niche with an example from Althorp. Norsk Geografisk Tidsskrift-Norwegian Journal of Geography, 54, 2000. p. 29-36.

CAMPELO, Graça. Ações pelo patrimônio. In: WEFFORT, Francisco; SOUZA, Mário. (Orgs.). Um Olhar Sobre a Cultura Brasileira. Rio de Janeiro: Associação de Amigos da FUNARTE, 1998. p. 12 .

CARRASCO, Gessonia Leite de A. Preservação de Artefatos Ornamentais de Ferro Integrados à Arquitetura. Estudo de Caso: Cemitério do Imigrante, Joinville, SC. 2009. 140 f. Dissertação (Mestrado em Arquitetura e Urbanismo) - Centro Tecnológico, Universidade Federal de Santa Catarina, Florianópolis, 2009.

CASTRO, Elisiana T. Aqui também jaz um patrimônio: identidade, memória e preservação patrimonial a partir do tombamento de um cemitério (o caso do Cemitério do Imigrante de Joinville/SC, 1962-2008). 2008. 210 f. Dissertação (Mestrado em Urbanismo, História e Arquitetura da Cidade) - Programa de Pós-Graduação em Urbanismo, História e Arquitetura da Cidade, Universidade Federal de Santa Catarina, Florianópolis, 2008.

CHARLET, Christian. Le Père-Lachaise: au coeur du Paris des vivants et des morts. Paris: Gallimard, 2003.

COELHO, António Matias. Abordar a Morte, Valorizar a Vida. In: (Coord.). Atitudes

Perante a Morte. Coimbra: Livraria Minerva, 1991. p. 7-11.

CRAIK, Jennifer. The culture of tourism. In: ROJEK, Cris; URRY, John. Touring cultures: Transformations of travel and theory. New York: Routlege, 1997. p. 113-136.

DIAS, Reinaldo; AGUIAR, Marina Rodrigues de. Fundamentos do Turismo. São Paulo: Alínea, 2002.

FOLEY, Malcolm; LENNON, J. John. JKF and Dark Tourism: A Fascination With Assassination. International Journal of Heritage Studies, v. 2, issue 4, p. 198-211, 1996.

FREYRE, Gilberto. Guia Prático, Histórico e Sentimental da Cidade do Recife. $5^{\text {a }}$ ed. São Paulo: Global Editora, 2013. [1934]

GONÇALVES, José Reginaldo S. Antropologia dos Objetos: coleções, museus e patrimônios. Rio de Janeiro: MinC/IPHAN/DEMU, 2007.

IMHOF, Afonso. Bem cultural: um patrimônio singular. A Notícia, Joinville, 15 ago. 1999.

Disponível em: <http://an.uol.com.br/1999/ago/15/0cid.htm>. Acesso em: 20 set. 2013.

LENNON, J. John; FOLEY, Malcolm. Dark Tourism: The Attraction of Death and Disaster. Londres: Continuum, 2000.

LIMA, Tânia de A. De morcegos e caveiras a cruzes e livros: a representação da morte nos cemitérios cariocas do século XIX (estudo de identidade e mobilidade social). Anais do Museu Paulista, São Paulo, v. 2, jan./dez., 1994. p. 87-150. 
MARTINS, José de Souza. A Morte e o Morto: tempo e espaço nos ritos fúnebres da roça. In: (Org.). A Morte e os Mortos na Sociedade Brasileira. São Paulo: Hucitec, 1983. p. 258-

269.

Anotações do meu caderno de campo sobre a cultura funerária no Brasil. In: OLIVEIRA, Marcos F. de; CALliA, Marcos H. P. (Orgs.). Reflexões Sobre a Morte no Brasil. São Paulo: Paulus, 2005. p. 73-91.

MELLO, J. A. G. de. Ingleses em Pernambuco. História do Cemitério Britânico e da participação de ingleses e outros estrangeiros na vida e na cultura de Pernambuco, no período de 1813 a 1909. Recife: Instituto Arqueológico, Histórico e Geográfico Pernambucano, 1972.

MOESCH, Marutschka. A Produção do Saber Turístico. $2^{\text {a }}$ ed. São Paulo: Contexto, 2002.

OSMAN, Samira Adel; RIBEIRO, Olívia Cristina Ferreira. Arte, história, turismo e lazer nos cemitérios da cidade de São Paulo. Licere, Belo Horizonte, v. 10, n.1, p. 1-15, abr. 2007. Disponível em: 〈http://www.anima.eefd.ufrj.br/licere/pdf/licereV10N01_a6.pdf〉. Acesso em: 15 abr. 2013.

PARAÍSO, Rostand. Esses Ingleses... Recife: Bagaço, 1997.

PELEGRINI, Sandra. Cultura e natureza: os desafios e as práticas preservacionistas na esfera do patrimônio cultural e ambiental. In: Revista Brasileira de História, n.51, 2006. Disponível em: <http://www.scielo.br/pdf/rbh/v26n51/07.pdf>. Acesso em: 17 mai. 2009.

PEREIRA, Cristina da Costa. Turismo Cemiterial. Instituto Superior da Maia. Disponível em <http://www.trabalhosfeitos.com/ensaios/Turismo-Cemiterial/557759.html.> Acesso em: 23 set. 2013.

PIRES, Maria Coeli S. Da Proteção ao Patrimônio Cultural: o tombamento como principal instituto. Belo Horizonte: Livraria Del Rey, 1994.

QUEIROZ, Francisco. Os cemitérios históricos e o seu potencial turístico em Portugal. In: Anuário 21 Gramas, n. 1, 2007, p. 7-12. Disponível em: <http://www.21 gramas.com>. Acesso em: 30 out. 2014.

RAGON, Michel. L'espace de la mort. Essai sur l'architecture, la décoration et l'urbanisme funéraires. Paris: Editions Albin Michel, 1981.

REZENDE, Eduardo Coelho M. Cemitérios. São Paulo: Necrópolis, 2007.

RICHARDS, Greg; BONINK, C. A. M. European Cultural Tourism Markets. Journal of Vacation Marketing, 1 (2), p. 173-180, 1995.

RODRIGUES, Cláudia. Nas Fronteiras do Além: a secularização da morte no Rio de Janeiro (séculos XVIII e XIX). Rio de Janeiro: Arquivo Nacional, 2005.

SEATON, A. V. Guided by the dark: From Thanatopsis to thanatourism. International Journal of Heritage Studies, 2 (4), 1996, p. 234-244.

SHARPLEY, Richard (2009). Shedding Light on Dark Tourism: An Introduction. In: SHARPLEY, Richard; STONE, Philip R. (Edits.). The Darker Side of Travel: The Theory and Practice of Dark Tourism. Bristol: Channel View Publications, 2009. p. 3-32

SILVA, José A. Ordenamento Constitucional da Cultura. São Paulo: Malheiros, 2001.

STONE, Philip R. A Dark Tourism spectrum: Towards a Typology of Death and Macabre Related Tourist Sites, Attractions and Exhibitions. Tourism: An Interdisciplinary International Journal, 54 (2), pp. 145-160, 2006. 
THOMAS, Louis-Vincent. Préface. In: URBAIN, Jean-Didier. La Société de Conservation. Étude sémiologique des cimetières d'Occident. Paris: Payot, 1978. p. 9-14. 